\title{
ANÁLISE ESTRUTURAL DE FLORESTAS DE RESTINGA ASSOCIADAS A DEPÓSITOS MARINHOS PLEISTOCÊNICOS E HOLOCÊNICOS NA BACIA DO RIO ITAGUARÉ, BERTIOGA (SP)
}

\author{
Felipe de Araújo PINTO SOBRINHO \\ Celia Regina de Gouveia SOUZA \\ Jaime E. de J. BADEL MOGOLLÓN
}

\begin{abstract}
RESUMO
As relações entre as fitofisionomias de vegetação de "Restinga" e o substrato sedimentar presentes nas planícies costeiras brasileiras ainda são pouco conhecidas. Este trabalho apresenta os aspectos estruturais do componente arbóreo de dois tipos de florestas de Restinga (Floresta baixa - FbR e Floresta alta - FaR) associadas a três depósitos marinhos quaternários de diferentes gerações, presentes na planície costeira da bacia do Rio Itaguaré, em Bertioga (SP), e descreve as variações espaciais nos teores de alguns elementos químicos do solo, associados a esses remanescentes florestais. Para o estudo da vegetação foi empregado o método de parcelas, que estabelece a análise de todos os indivíduos com DAP (diâmetro à altura do peito) $\geq 10 \mathrm{~cm}$. Os parâmetros levantados foram densidade, área basal e altura dos indivíduos. Os resultados mostraram que a FbR apresenta as menores amplitudes diamétricas e alturas dos indivíduos arbóreos e menor dispersão das alturas quando correlacionadas com o diâmetro (relação alométrica entre altura e DAP). Na FaR foi possível identificar variações na estrutura em função da idade do depósito marinho, do quimismo e da evolução dos solos associados, de forma que a floresta se apresenta melhor desenvolvida nos depósitos mais antigos, além de mostrar a maior correlação positiva para a relação alométrica. Percebe-se também a importância da camada orgânica depositada sobre o solo para o equilíbrio da dinâmica da ciclagem dos nutrientes disponibilizados para as plantas. De acordo com os parâmetros da legislação ambiental vigente as fitofisionomias estudadas encontram-se em estágio avançado de regeneração (FbR) e em estado primário ou nativo (FaR).
\end{abstract}

Palavras-chave: estrutura florestal, Restinga, depósitos marinhos quaternários, fertilidade de solos, variação espacial.

\section{ABSTRACT}

In the Brazilian coastal plains, the relationship between the "Restinga" phytophysiognomies and sedimentary deposits are still poorly understood. This paper presents the main structural aspects of tree components from two types of Restinga forests (Restinga low Forest - FbR, and Restinga high Forest - FaR), which cover three different generations of marine deposits outcropping in the coastal plain area of the Itaguaré River basin, Bertioga (SP), and also describes the spatial variations in the concentrations of some chemical elements in soil, associated with these forest remnants. The parcel method assumed that all individuals have $\mathrm{DBH} \geq 10 \mathrm{~cm}$. Density, basal area and tree height were measured. The results show that in FbR, the trees have the smallest diameters and heights, as well as little relationship between DBH and height. Considerable variations occur in the two types of FaR as a function of marine deposit age, soil evolution and chemical properties; so that the best developed forest covers the most ancient deposits with the most evolved and richest soils. The organic layer deposited on top of the soil is very important for balancing the dynamics of the cycling of nutrients available to plants. According to the environmental law CONAMA $n^{\circ} 07 / 1996$, these phytophysiognomies are still well-preserved, since they are in advanced stage of regeneration in FbR, and are primary or native in FaR.

Keywords: forest structure, "Restinga" vegetation, marine deposits, Quaternary, soil fertility, spatial variability. 


\section{INTRODUÇÃO}

Atualmente, no Estado de São Paulo, restam apenas $13,24 \%$ da cobertura original do bioma Mata Atlântica, dos quais 12,11\% correspondem à Mata Atlântica propriamente dita (florestas Ombrófila Densa, Ombrófila Mista, Ombrófila Aberta, Estacional Semidecidual, Estacional Decidual), $1,02 \%$ à vegetação de restinga e $0,11 \%$ aos manguezais (SOSMA/INPE 2008).

Apesar desse quadro, a zona costeira de São Paulo ainda guarda grande diversidade de ambientes naturais, destacando os extensos maciços bem preservados de diversas fitofisionomias que recobrem as planícies costeiras e as baixas e médias encostas da Serra do Mar. Segundo Souza et al. (2008), estas são denominadas inadequadamente de "Vegetação de Restinga" pela Resolução CONAMA n 7 de 23 de julho de 1996, uma vez que o termo "restinga" tem vários significados (geológico- geomorfológico, ecológico, botânico), o que tem causado problemas na aplicação da legislação ambiental pertinente.

O município de Bertioga, situado na Região Metropolitana da Baixada Santista, apresenta uma planície costeira de $640 \mathrm{~km}^{2}$ de área (BADEL-MOGOLLÓN \& SOUZA 2010), onde grande parte da vegetação ainda se encontra bem preservada ou em estado original.

Estudos recentes realizados principalmente nas bacias dos rios Itaguaré e Guaratuba (SOUZA 2007, LOPES 2007, MOREIRA 2007, SOUZA et al. 2009, MARTINS 2009) têm destacado a importância e a complexidade desses ambientes e a interação entre os seus aspectos abióticos e bióticos, responsáveis pela ampla geobiodiversidade observada.

Nessas bacias são encontradas praticamente todas as fitofisionomias florestais descritas na Resolução CONAMA no 07/1996 (Floresta baixa de Restinga, Floresta alta de Restinga, Floresta Paludosa, Floresta de Transição Restinga-Encosta) e ainda mais dois tipos novos de vegetação, denominados informalmente de Floresta alta de Restinga Úmida (também encontrada no Litoral Norte, segundo SOUZA \& LUNA 2008) e Floresta Aluvial (LOPES 2007, SOUZA et al. 2009).

Toda essa matriz vegetacional recobre importantes registros da evolução quaternária das planícies costeiras paulistas, incluindo: ambientes sedimentares pleistocênicos da Formação Cananéia (terraços marinhos e fluviais associa- dos) e holocênicos da Formação Ilha Comprida (depósitos marinhos-praias, eólicos, estuarino-lagunares, paludiais, lacustres, fluviais e coluviais), além de depósitos recentes de origens praial e continental (depósitos aluviais, coluviais de baixada e de encosta) (SOUZA 2007, SOUZA et al. 2009).

Os diversos tipos de substratos geológicos e solos associados guardam estreita relação com variados tipos de fitofisionomias, cujas associações encontradas nas bacias dos rios Itaguaré e Guaratuba foram denominadas por SOUZA et al. (2009) de sub-biomas de planície costeira e baixa encosta (Figura 1).

Neste contexto, o presente estudo apresenta a caracterização da estrutura dos remanescentes de vegetação que formam três desses sub-biomas presentes na planície costeira da bacia do Rio Itaguaré: Floresta baixa de Restinga sobre Cordões Litorâneos Holocênicos, Floresta alta de Restinga sobre Terraços Marinhos Holocênicos e Floresta alta de Restinga sobre Terraço Marinho Baixo Pleistocênico (Figura 1).

O presente trabalho visa contribuir também para a melhor compreensão dessas florestas, com um arcabouço teórico que poderá subsidiar a elaboração do Plano de Manejo do Parque Estadual Restinga de Bertioga, bem como embasar trabalhos de recuperação e restauração de ambientes similares no litoral paulista.

\section{2 ÁREA DE ESTUDO}

O Município de Bertioga, cuja coordenada central é $23^{\circ} 51^{\prime} \mathrm{S}$ e $46^{\circ} 08^{\prime} \mathrm{W}$, possui área total de $482 \mathrm{~km}^{2}$, que corresponde a $20,3 \%$ de todo o território da Região Metropolitana da Baixada Santista.

O clima, segundo a classificação de Koppen, é do tipo tropical, apresentando temperatura média do mês mais quente superior a $18^{\circ} \mathrm{C}$, total de chuvas do mês mais seco superior a $60 \mathrm{~mm}$ e precipitação anual variando de 1.600 a 2.000 mm; não possui estação seca invernal, apenas diminuição de pluviosidade, enquanto os verões são excessivamente úmidos (ROSSI 1999).

O município é drenado pelas bacias hidrográficas dos rios Itapanhaú, Itaguaré e Guaratuba. Recentemente, a maior parte dos territórios das bacias dos rios Itaguaré e Guaratuba e o segmento leste da bacia do Rio Itapanhaú foram englobadas em uma Unidade de Conservação integral denominada "Parque Estadual da Restinga de Bertioga", que 


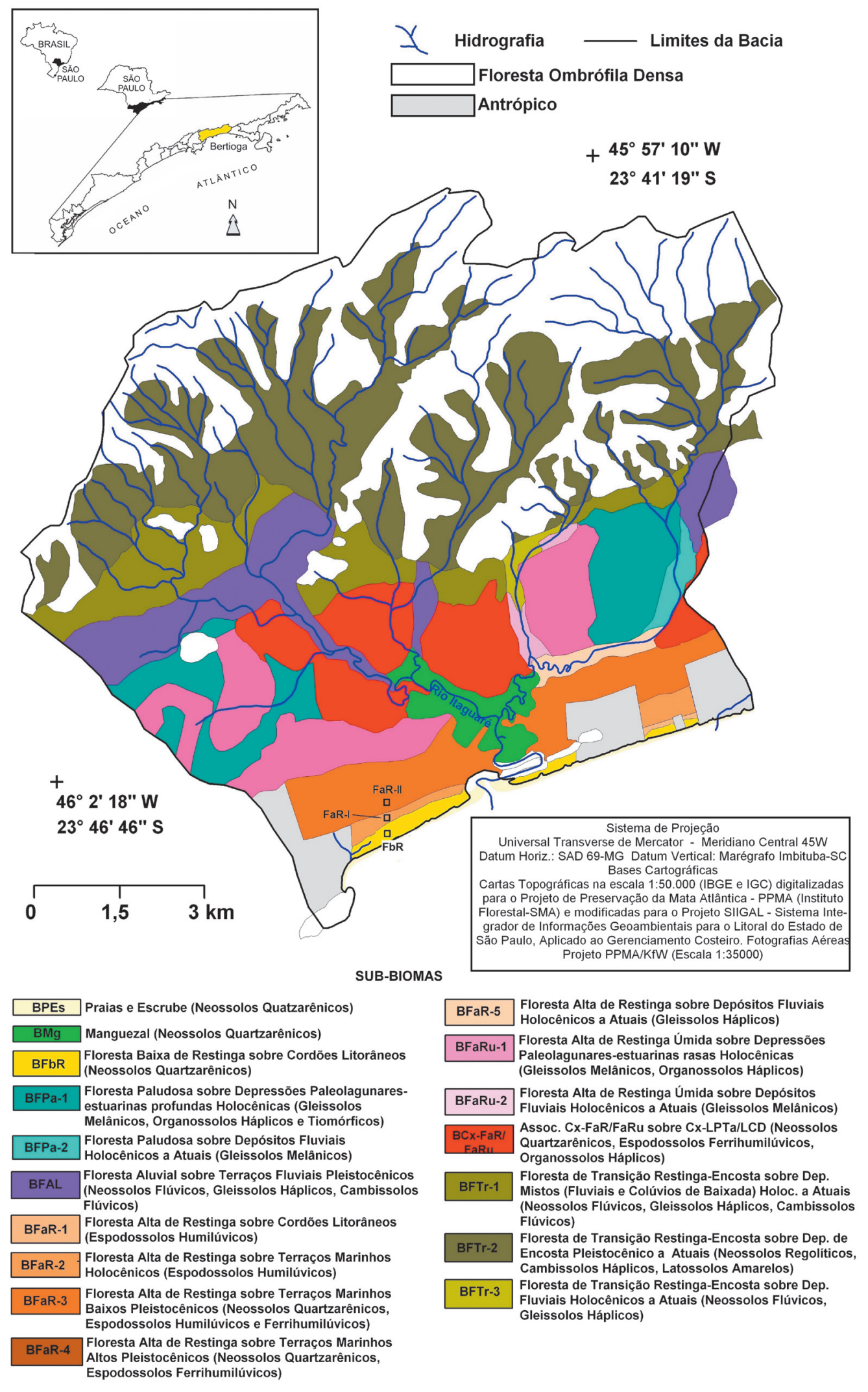

FIGURA 1 - Sub-biomas de planície costeira e baixa-média encosta na bacia do Rio Itaguaré, Bertioga/SP (Baseada em SOUZA et al. 2009). 
abrange 9.312,32 ha (Decreto Estadual $\mathrm{n}^{\mathrm{o}} 56.500$ de 09/12/2010).

A área de estudo pertence à bacia do Rio Itaguaré, que ocupa uma área de $89,91 \mathrm{~km}^{2}$, cerca de $19 \%$ do território municipal. Praticamente toda sua área está coberta por vegetação nativa, atualmente protegida por unidades de conservação.
$\mathrm{Na}$ planície costeira do Itaguaré ocorrem quatro gerações de depósitos marinho-praiais quaternários (duas pleistocênicas e duas holocênicas), dispostos paralelamente à linha de costa desde a praia, depósitos paleoestuarino-lagunares e alguns tipos de depósitos continentais interiorizados (SOUZA 2007) (Figura 2).

\section{Seção Esquemática: Unidades Quaternárias da Planície Costeira do Itaguaré (SEM ESCALA VERTICAL)}
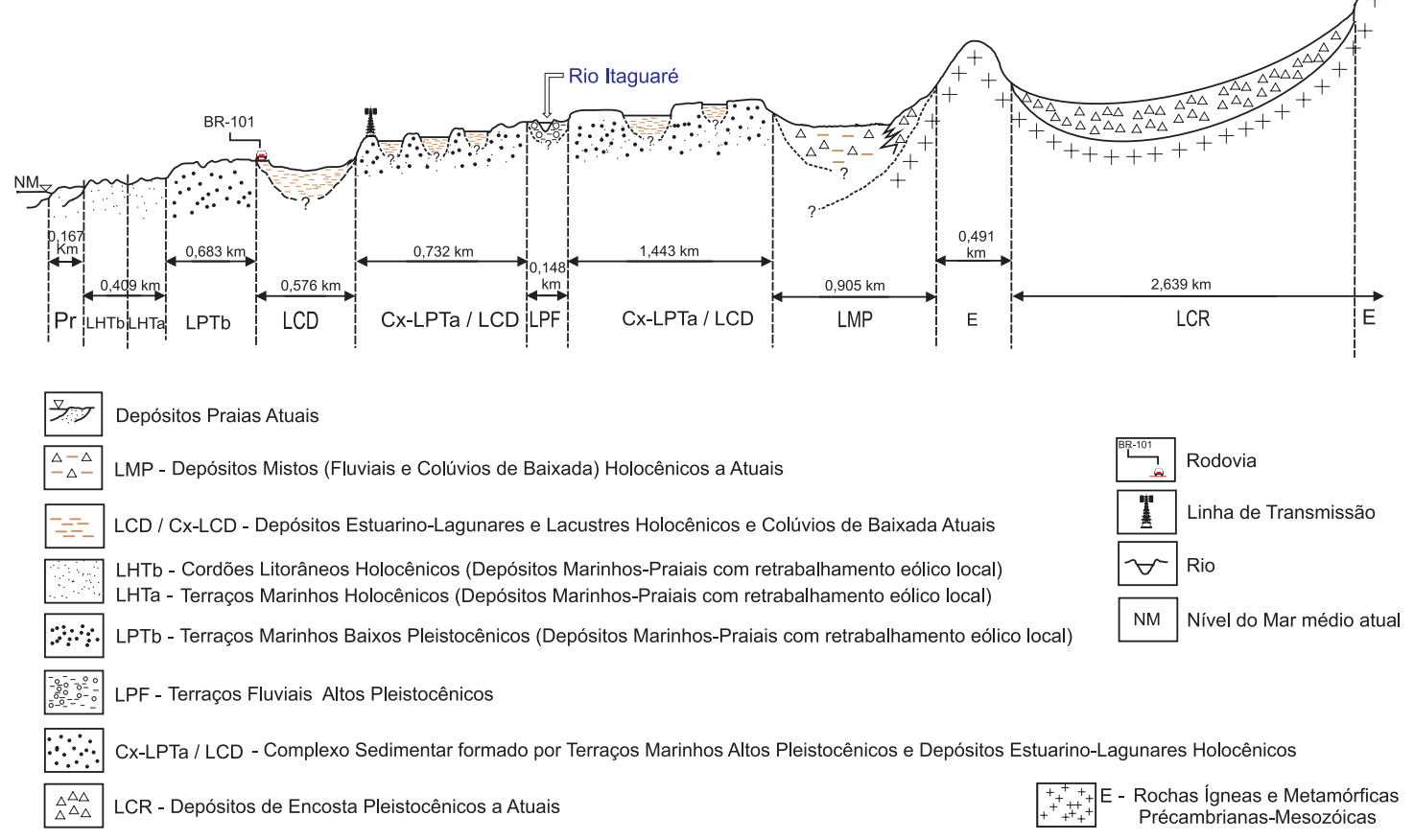

FIGURA 2 - Seção esquemática representativa das Unidades Quaternárias da planície costeira de Itaguaré (Modificada de MOREIRA 2007, baseada em SOUZA 2007).

As florestas caracterizadas no presente estudo desenvolveram-se sobre as Unidades Quaternárias LHTa, LHTb e LPTb, descritas a seguir, conforme trabalhos de SOUZA (2007), MOREIRA (2007) e SOUZA et al. (2008).

- LHTa e LHTb: compreendem duas gerações de depósitos arenosos (areias muito finas a finas, muito bem a bem selecionadas) de origem marinha-praial, que apresentam respectivamente feições de cordões litorâneos (morfologia original bem preservada) e terraços marinhos mais baixos (morfologia original de cordões parcialmente preservada), com retrabalhamentos eólicos no topo. A primeira geração (LHTa) é mais elevada (cotas en- tre 3 e $4 \mathrm{~m}$ acima do nível do mar atual), mais antiga e encontra-se mais afastada da linha de costa (distal), formando terraços amplos. A segunda geração (LHTb) é mais baixa (cotas entre 1,5 a 2,5 m), mais jovem e bem próxima da linha de costa atual (frontal) e preserva a morfologia de cordões litorâneos. Ambas são correlatas à Formação Ilha Comprida, portanto geradas durante o evento Transgressivo-Regressivo Santos. De acordo com SUGUIO \& MARTIN (1976) esse evento teve seu máximo transgressivo por volta de 5.100 ${ }^{14} \mathrm{C}$ anos A.P. (5.600 cal anos AP, segundo MARTIN 2003), mas sofreu oscilações de subida e descida do nível relativo do mar, com uma pequena transgressão por volta 
de 3.200 anos A.P. A segunda geração seria atribuída à regressão marinha subsequente a essa pequena transgressão.

- LPTb: geração de depósito arenoso (areias finas muito bem a bem selecionadas) marinho, que apresenta feição de terraço marinho mais elevado que os holocênicos, podendo apresentar retrabalhamentos eólicos no topo. As altitudes variam entre 5 e $8 \mathrm{~m}$, sendo formada por amplos terraços marinhos que se estendem lateralmente de forma contínua. Essa formação é correlata à Formação Cananéia, associada ao evento Transgressivo-Regressivo Cananéia, cujo máximo transgressivo ocorreu em 120.000 A.P. (SUGUIO \& MARTIN 1978).

Segundo MARTINS (2009) a maturidade mineralógica desses depósitos marinhos, definida pelos índices ZTR (Zircão-Turmalina-Rutilo), aumenta da praia para o interior da planície costeira, atestando o aumento progressivo das idades desses depósitos.

Datações por LOE obtidas por MARTINS (2009) para sedimentos coletados a $1,10 \mathrm{~m}$ de profundidade em LHTb e LHTa, nas bacias dos rios Itaguaré e Itapanhaú, indicaram idades entre $5.100 \pm 1.000$ e $6.600 \pm 500$ anos A.P. Para LPTb, sedimentos coletados a $1,05 \mathrm{~m}$ de profundidade na bacia do Rio Itapanhaú, a idade LOE obtida foi de $42.700 \pm 3.500$ anos A.P.
Em relação aos solos, em LHTb ocorrem Neossolos Quartzarênicos, em geral, hidromórficos, enquanto em LHTa e LPTb predominam os Espodossolos Humulúvicos (ROSSI 1999, MOREIRA 2007, MARTINS 2009). Esses solos apresentam os menores teores de argila de todos os solos encontrados nas planícies em Bertioga, sempre inferiores a $5 \%$, teores de silte de $6 \%$ e os maiores teores de areia total, sempre superiores a $90 \%$. Datações da matéria orgânica dos espodossolos em LHTb na bacia do Rio Itapanhaú revelaram idades da ordem de 4.260 anos A.P. (MARTINS 2009).

Nessas três gerações de depósitos marinho-praiais ocorrem três tipos de florestas de Restinga (figuras 1 e 3), objeto do presente estudo: Floresta baixa de Restinga (FbR) sobre Cordões Litorâneos Holocênicos (LHTb), que compõe o sub-bioma SB-FbR; Floresta alta de Restinga (FaR-I) sobre Terraços Marinhos Holocênicos (LHTa), definida pelo sub-bioma SB-FaR-2; e Floresta alta de Restinga (FaR-II) sobre Terraços Marinhos Pleistocênicos (LPTb), associada ao sub-bioma SB-FaR-3.

\section{MATERIAIS E MÉTODOS}

As tipologias florestais foram inventariadas pelo método de parcelas; para cada Unidade Quaternária foram alocadas, aleatoriamente, duas parcelas de $20 \times 25 \mathrm{~m}$.

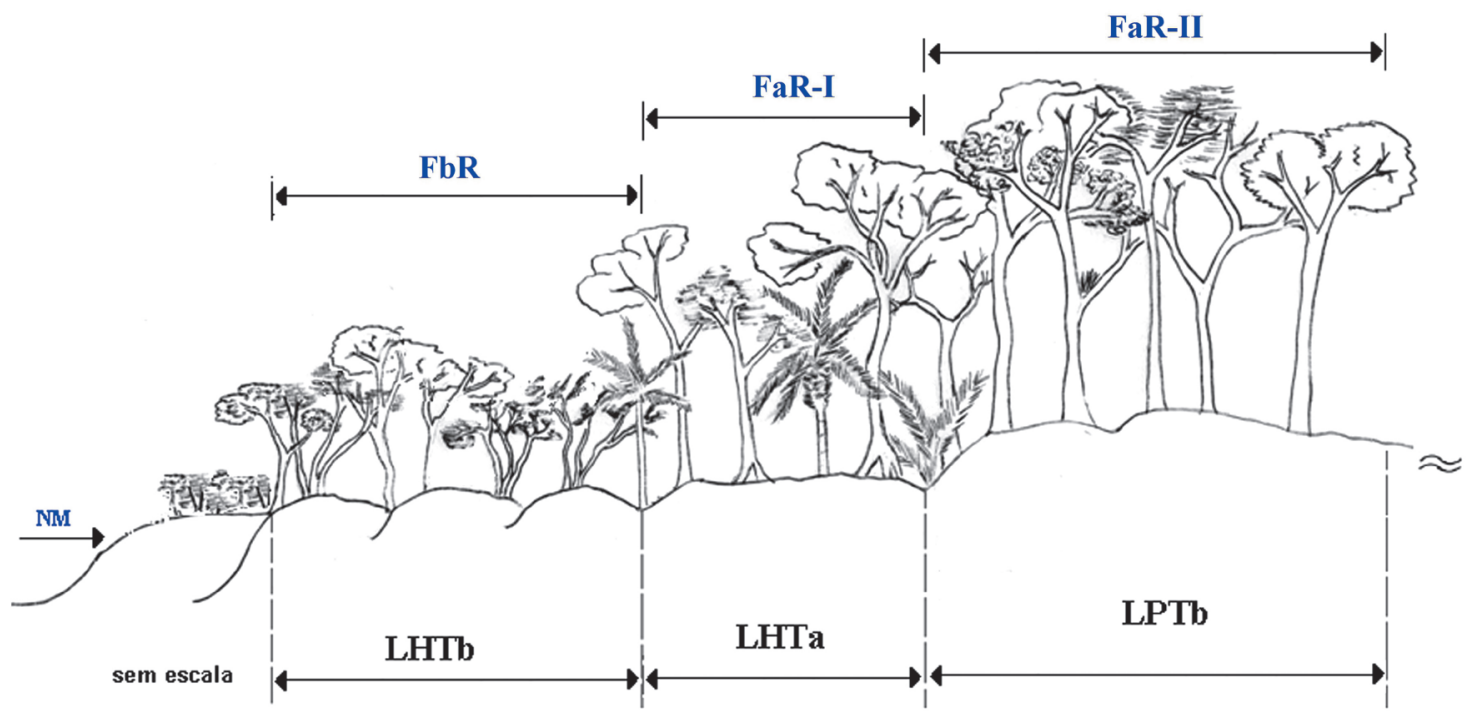

FIGURA 3 - Associações entre as Unidades Quaternárias e as fitofisionomias florestais encontradas na área de estudo. 
Todos os indivíduos arbóreos com diâmetro a altura do peito (DAP) $\geq 10 \mathrm{~cm}$ foram marcados com placas numeradas de alumínio e mensurados.

A estrutura vertical das florestas foi analisada conforme o critério de estratificação, recomendado por SOUZA et al. (1996), que divide a floresta nos seguintes estratos de altura: Estrato inferior (EI), Estrato médio (EM) e Estrato superior (ES). As alturas dos limites entre os três estratos foram calculados pelas seguintes expressões:

$$
\begin{aligned}
& E I: H<(H m-1 \sigma) \\
& E M:(H m-1 \sigma) \leq H<(H m+1 \sigma) \\
& E S: H \geq(H m+1 \sigma)
\end{aligned}
$$

onde: $\mathrm{H}$ - altura total; $\mathrm{Hm}$ - Altura média; $\sigma-$ desvio padrão das alturas.

Os parâmetros estruturais horizontais - área basal e estrutura diamétrica - foram calculados por meio do programa computacional Mata Nativa 2.

Com base na análise química de amostras de solos obtidos nos primeiros $20 \mathrm{~cm}$ de profundidade (zona fértil desses solos), coletadas por MOREIRA (2007) nas mesmas Unidades Quaternárias do presente estudo, foram calculadas as médias dos valores dos seguintes componentes: MO (matéria orgânica), pH, C (carbono), P (fósforo), $\mathrm{K}$ (potássio), $\mathrm{Ca}$ (cálcio), $\mathrm{Mg}$ (magnésio) e $\mathrm{Al}$ (alumínio).

O comportamento espacial das variáveis químicas dos solos foi feito a partir da avaliação geoestatística da MO, Capacidade de Troca Catiônica (CTC), T (CTC a pH 7), Saturação por Bases (V\%), Soma de Bases (SB) e Alumínio (m\%). A análise geoestatística foi feita com auxílio do software GS+® (versão 5.0) e incluiu a análise de semivariância e de regressão e, posteriormente, a interpolação, efetuada pelo método de krigagem (CTC, T, $\mathrm{SB}, \mathrm{pH}, \mathrm{m} \%$ ) e cokrigagem (MO e Alumínio).

\section{RESULTADOS E DISCUSSÃO}

\subsection{Estrutura das florestas}

Observou-se diferenças estruturais entre as florestas originalmente descritas como Florestas baixa $(\mathrm{FbR})$ e alta $(\mathrm{FaR})$ de Restinga, e também no interior da própria Floresta alta de Restinga, que pôde ser subdividida fitofisionomicamente em FaR-I (associada aos terraços marinhos holocênicos) e FaR-II (associada aos terraços marinhos pleistocênicos). Apesar de menos expressiva, também houve diferenças no desenvolvimento estrutural. Essas diferenças corroboram a existência de diferentes sub-biomas nessas unidades quaternárias, como postulado por SOUZA et al. (2009).

No total foram mensurados 265 indivíduos arbóreos, perfazendo uma área basal $(\mathrm{AB})$ acumulada de $8,3 \mathrm{~m}^{2}$ e $\mathrm{AB} /$ ha acumulada de $83,0 \mathrm{~m}^{2}$ (Tabela 1 ). A menor $\mathrm{AB}$ foi obtida na FbR e a maior na FaR-II. Em relação ao DAP, os menores valores médios foram encontrados na FbR e os maiores na FaR-II. As alturas mínimas foram de 7,5 m em FaR-II, $8 \mathrm{~m}$ em FbR e $9 \mathrm{~m}$ em FaR-I, enquanto as máximas foram de 30 m, obtidas nas duas áreas de FaR.

A FbR apresenta dossel aberto, o que permite a entrada de bastante luminosidade no interior da floresta (Figura 4a). Quando comparada às demais, esta fitofisionomia caracteriza-se por maior densidade estimada de indivíduos arbóreos por hectare (980) e por apresentar muitas árvores perfilhadas, ou seja, com multi-fustes peculiaridade já apontada por LOPES (2007). O DAP médio dos indivíduos foi de $13,6 \mathrm{~cm}$ e a área basal estimada por hectare de $22,4 \mathrm{~m}^{2}$. A altura média da população foi de $9,5 \mathrm{~m}$. A superfície do solo apresenta fina camada de serapilheira, em média de $3 \mathrm{~cm}$.

TABELA 1 - Parâmetros estruturais das florestas estudadas. N/ha = densidade de indivíduos por hectare; $\mathrm{ABamost}$. = área basal da amostragem; $\mathrm{AB} / \mathrm{ha}=$ área basal por hectare; $\mathrm{DAP}=$ diâmetro a altura do peito; Alt = altura; $\min =$ mínima; $\max =$ máxima .

\begin{tabular}{cccccc}
\hline Floresta & N/ha & ABamost $\left(\mathrm{m}^{2}\right)$ & AB/ha $\left(\mathrm{m}^{2}\right)$ & Alt min & Alt max \\
\hline FbR & 980 & 2,24 & 22,4 & 8 & 15 \\
FaR-I & 790 & 2,7 & 27,0 & 9 & 30 \\
FaR-II & 880 & 3,35 & 33,5 & 7,5 & 30 \\
\hline Total & 2.650 & 8,29 & 83,0 & & \\
\hline
\end{tabular}



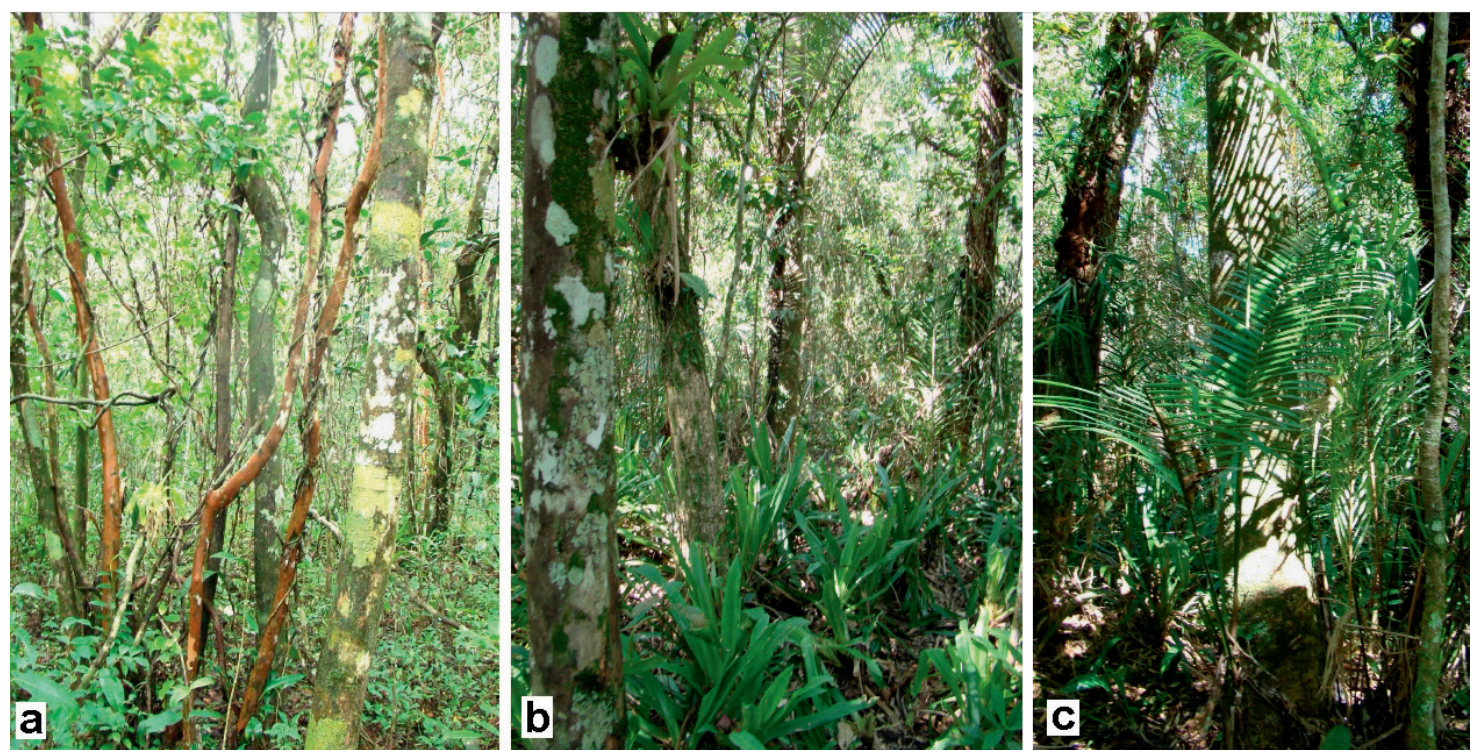

FIGURA 4 - Fitofisionomias estudadas na bacia do rio Itaguaré, Bertioga (SP): (a) FbR sobre cordões litorâneos holocênicos ; (b) FaR-I sobre terraços marinhos holocênicos; (c) FaR-II sobre terraços marinhos pleistocênicos.

Seguindo os parâmetros estruturais básicos para caracterizar os estágios de regeneração da Vegetação de Restinga no Estado de São Paulo, descritos na Resolução CONAMA n ${ }^{07 / 1996,}$ percebe-se que essa vegetação estruturalmente aproxima-se da FbR em estágio primário ou original.

Na FaR-I o dossel é fechado e com indivíduos emergentes, sendo comum a presença de epífitas arbóreas e terrestres (Figura 4b). Os indivíduos arbóreos alcançam em média $17 \mathrm{~m}$ de altura, enquanto os emergentes, até $30 \mathrm{~m}$. Estimou-se uma densidade de 790 indivíduos por hectare. O DAP médio foi de $15,4 \mathrm{~cm}$ e a área basal estimada por hectare de $27,0 \mathrm{~m}^{2}$. A serapilheira apresenta espessura média de aproximadamente $10 \mathrm{~cm}$.

A FaR-II apresenta dossel mais fechado e indivíduos emergentes com altura média de 17 $\mathrm{m}$, podendo atingir também até $30 \mathrm{~m}$ (Figura 4c). Apresenta maior densidade de indivíduos (880) por hectare que FaR-I e maior desenvolvimento do diâmetro dos fustes em relação às demais florestas, atingindo em média $16,3 \mathrm{~cm}$. Consequentemente, a área basal estimada por hectare também foi maior $\left(33,5 \mathrm{~m}^{2}\right)$. A espessura da serapilheira, de aproximadamente $18 \mathrm{~cm}$, também é maior do que nas demais florestas.

A densidade total de indivíduos por hectare encontrada no presente estudo para FaR-I (790) e FaR-II (880) é baixa quando comparada à da
Floresta alta de Restinga na bacia do rio Itapanhaú, também em Bertioga (1.737,5 ind./ha, GUEDES et al. 2006). A alta densidade de indivíduos encontrada por esses autores justifica-se principalmente pelo critério de inclusão dos indivíduos, que foi de $10 \mathrm{~cm}$ de PAP (perímetro à altura do peito).

As características estruturais de FaR-I e FaR-II coincidem com muitas das características da Floresta alta de Restinga em estágio primário ou original (Resolução CONAMA n ${ }^{0} 7 / 1996$ ). Quanto ao porte das árvores, as mesmas atingem em geral alturas superiores às descritas na Resolução (20 $\mathrm{m})$, com presença abundante de indivíduos emergentes. Em relação à amplitude diamétrica das árvores, nas duas áreas os valores coincidem com a variação média descrita na Resolução, que vai de 12 a $25 \mathrm{~cm}$, com alguns indivíduos ultrapassando os $40 \mathrm{~cm}$ (Figura 5).

As distribuições diamétricas das três comunidades também mostram um padrão comum às florestas nativas, conhecido como "J" invertido, caracterizado por grande estoque de indivíduos nas menores classes diamétricas e diminuição gradativa dos mesmos nas maiores classes de DAP (Figura 5). Segundo SCOLFORO et al. (1998), a maior concentração de indivíduos nas menores classes diamétricas pode caracterizar uma comunidade estoque, sendo um padrão das florestas tropicais maduras com idades e composição de espécies variáveis. 


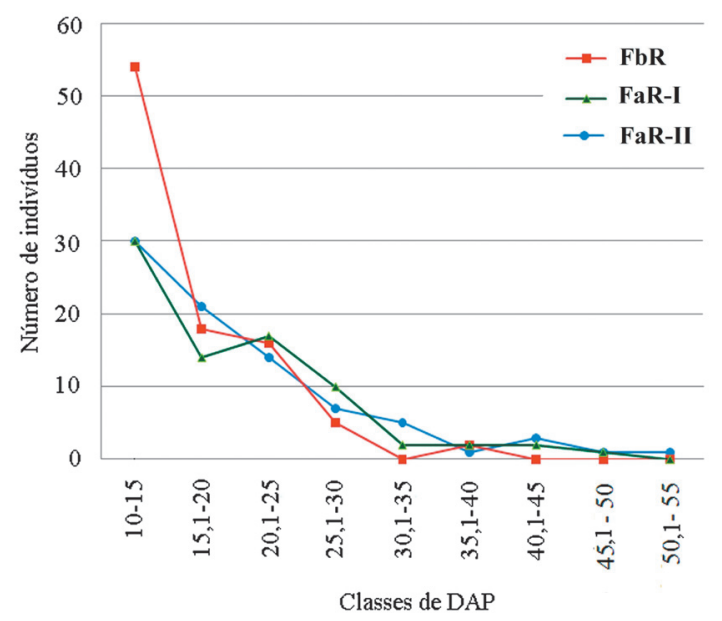

FIGURA 5 - Distribuição diamétrica dos indivíduos arbóreos amostrados nas três florestas.

$\mathrm{Na} F b R$ a maior quantidade de indivíduos está nas classes mais baixas entre $10-25 \mathrm{~cm}$, embora mais concentrada na classe de $10-15 \mathrm{~cm}$. Este fato já era esperado, uma vez que essa tipologia apresenta baixa área basal formada por uma grande densidade de indivíduos com fustes pouco desenvolvidos, que alcançam no máximo $35,5 \mathrm{~cm}$ de DAP. Outro aspecto interessante dessa floresta é a distribuição diamétrica desbalanceada, com ausência de indivíduos na classe de $30,1-35 \mathrm{~cm}$, reaparecimento de alguns na classe seguinte $(35,1-40 \mathrm{~cm})$ e ausência total nas demais classes.

Em FaR-I e FaR-II o maior número de indivíduos também está nas classes diamétricas mais baixas, de 10-25 cm. Entretanto, em ambas as florestas, as árvores alcançam classes mais altas de DAP, com FaR-I atingindo $50 \mathrm{~cm}$ e FaR-II, $55 \mathrm{~cm}$. Nessas duas áreas percebe-se a ocorrência frequente de grandes árvores tombadas, fato também comentado por LOPES (2007) e MOREIRA (2007) como um fenômeno comum a todas as fitofisionomias florestais presentes nas bacias dos rios Itaguaré e Guaratuba.

Esse fenômeno parece ser explicado pela ocorrência de raízes sempre pouco profundas (distribuídas a profundidades em geral inferiores a 60 $\mathrm{cm})$, solos muito friáveis, nível de lençol freático alto e clima caracterizado por muitas chuvas e ventos durante todo o ano (segunda área de maior pluviosidade do Brasil) (SOUZA et al. 2009). LAURENCE \& YENSEN (1991) associaram o aumento na taxa de mortalidade de indivíduos arbóreos adultos em florestas tropicais ao efeito de borda, que permitiria a maior entrada de ventos fortes no interior da floresta.
Aplicando o conceito de estratificação vertical das comunidades em três níveis estruturais (baixo, médio e alto) (Figura 6), percebe-se que nas três áreas há maior densidade de indivíduos no estrato médio. $\mathrm{Na} \mathrm{FbR} \mathrm{o} \mathrm{estrato} \mathrm{inferior} \mathrm{(EI)}$ englobou todos os indivíduos com altura menor que $8,13 \mathrm{~m}$, o estrato médio (EM), indivíduos com alturas entre 8,0 e $11,0 \mathrm{~m}$ e o estrato superior (ES), indivíduos maiores que $11 \mathrm{~m}$. Para a FaR-I, o EI foi representado por todos indivíduos menores que $13 \mathrm{~m}$, o EM, indivíduos entre 13 e $24 \mathrm{~m}$, e o ES, indivíduos maiores que $24 \mathrm{~m}$. Já a FaR-II teve seu EI representado por todos os indivíduos menores que 11,5 m, o EM, indivíduos entre 11,5 e $25,5 \mathrm{~m}$, e o ES, indivíduos maiores que $25,5 \mathrm{~m}$. Considerando o ES como o estrato emergente das florestas estudadas, percebe-se que dentre as três comunidades, FaR-II apresentou a maior maturidade em altura, devido ao maior número de árvores emergentes (22).

Segundo SOUZA et al. (2003) a análise da estratificação vertical da floresta é importante, pois é um indicador de riqueza, diversidade, crescimento e produção de biomassa, sendo um excelente indicador de sustentabilidade ambiental, uma vez que nos estratos verticais de uma floresta natural coexistem diferentes grupos de plantas e animais que ocupam diferentes nichos. Nesse sentido, dentre as três áreas, FbR apresentou a menor amplitude de altura dos indivíduos dentro de cada estrato, sendo que seu estrato superior se enquadra na amplitude do estrato médio das outras duas florestas estudadas. Isto indica que as duas florestas altas de Restinga apresentam maior maturidade estrutural que a FbR.

A análise da relação alométrica entre a altura e o DAP nas três áreas amostrais (Figura 7) evidencia padrões distintos. Apesar de todas apresentarem uma correlação positiva pelo teste de Pearson (Figura 7), a maior correlação foi obtida para FaR-II $(\mathrm{r}=0,76 ; \mathrm{p}<0,0001 ; \alpha=0,05)$. FaR-I $(\mathrm{r}=$ $0,61 ; \mathrm{p}<0,0001 ; \alpha=0,05)$ apresentou uma correlação mais dispersa que FaR-II. A FbR apresentou a menor correlação $(r=0,47 ; p<0,0001 ; \alpha=0,05)$, devido à baixa dispersão da distribuição das alturas em relação ao aumento dos diâmetros. À medida que isso ocorre, a altura das árvores tende a permanecer constante, não ultrapassando os $11 \mathrm{~m}$, salvo raras exceções.

4.2 Fatores que podem influenciar a estrutura das Florestas de Restinga

São muitos os fatores que podem influenciar na tipologia e estrutura das florestas de Restinga, 

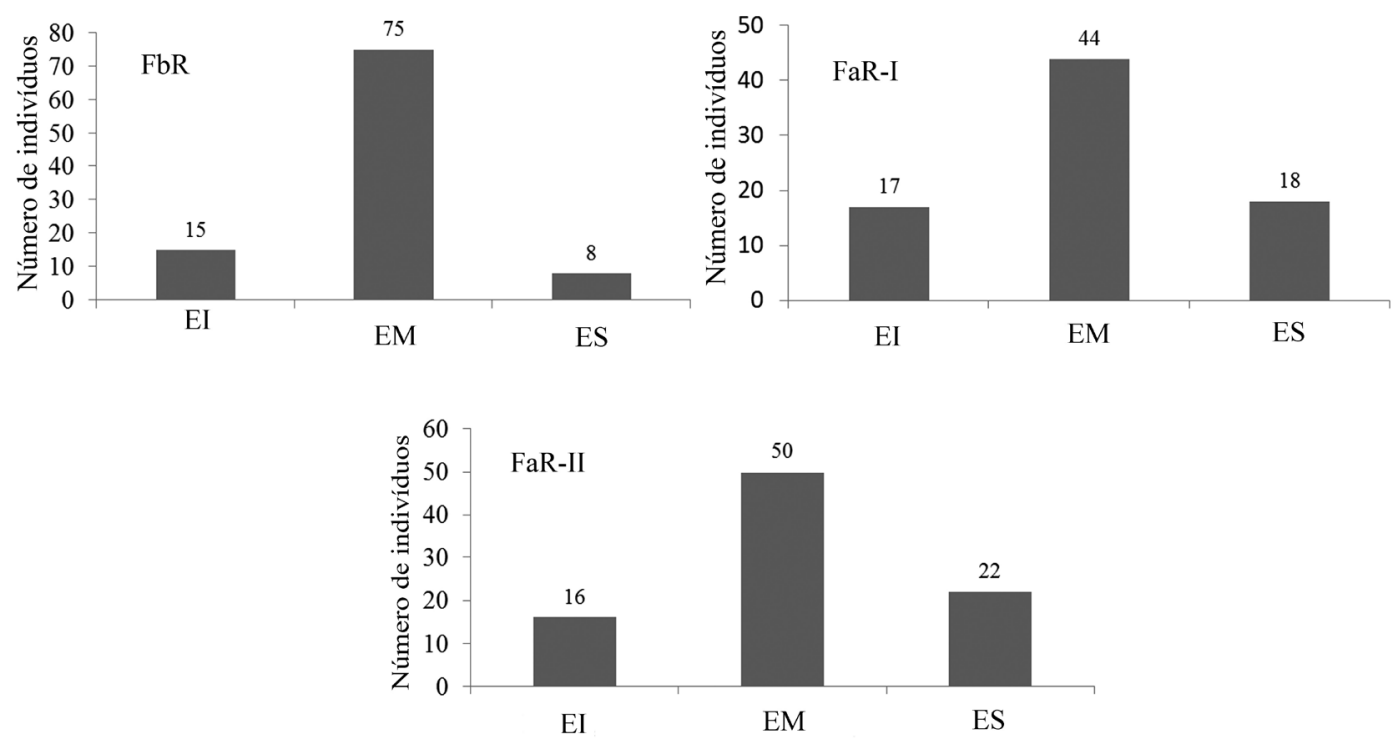

FIGURA 6 - Estrutura vertical dos indivíduos arbóreos da área de estudo (EI = estrato inferior, EM = estrato médio e ES = estrato superior).
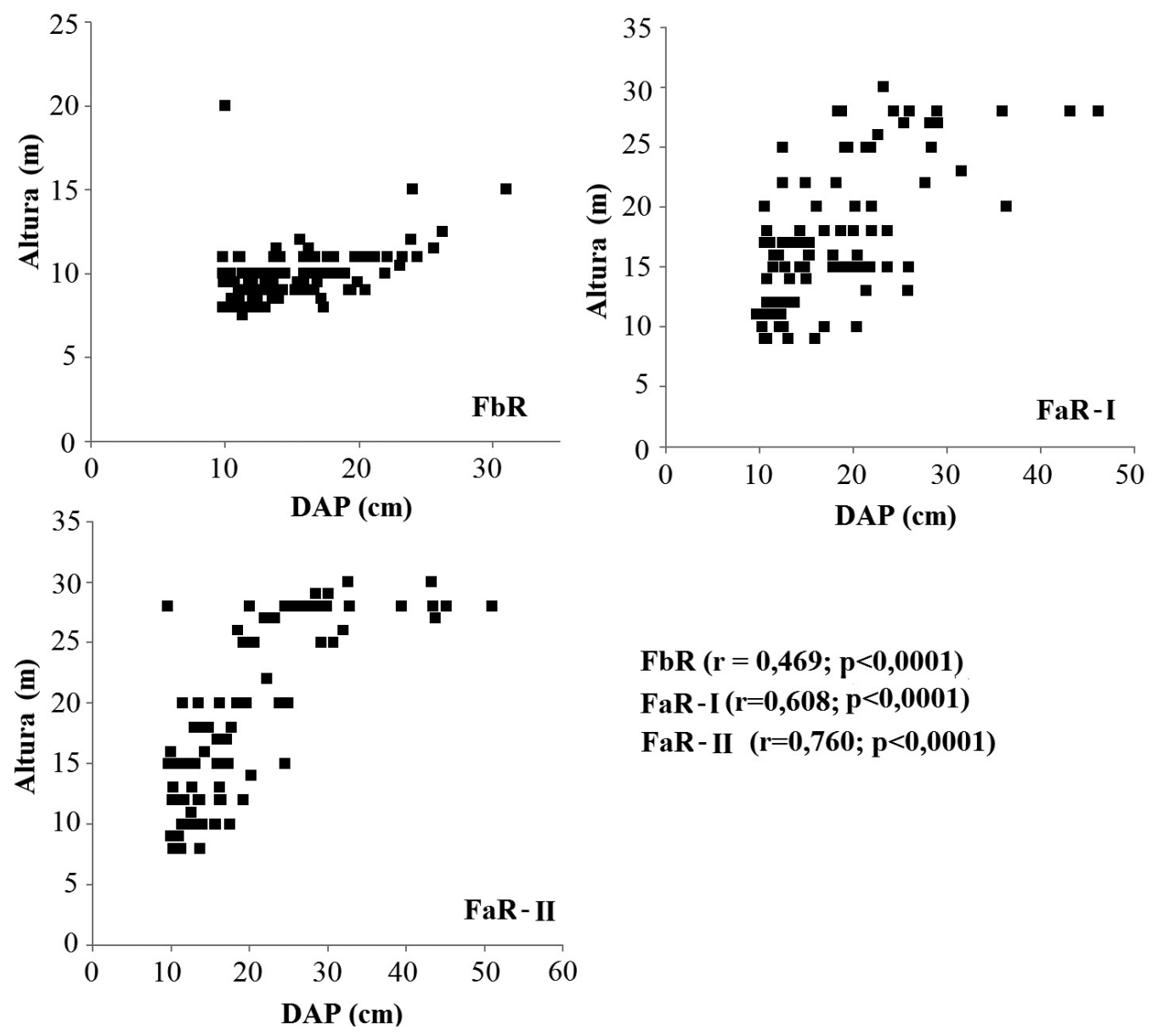

$\operatorname{FbR}(r=0,469 ; p<0,0001)$

FaR - I $(r=0,608 ; p<0,0001)$

FaR- II $(r=0,760 ; p<0,0001)$

FIGURA 7 - Relação alométrica entre altura $(\mathrm{m})$ e DAP $(\mathrm{cm})$ dos indivíduos arbóreos amostrados nas áreas de estudo. 
incluindo atributos geológicos, geomorfológicos, edáficos, pedológicos, hidrológicos, climatológicos, biológicos e até antrópicos.

Neste sentido, é importante considerar também que os padrões fitofisionômicos e o estágio atual da paisagem envolvem processos de diferentes escalas temporais e espaciais, desde a autociclagem contínua de nutrientes no solo, pela deposição da serapilheira, até a evolução geológica, geomorfológica e pedológica dos ambientes sedimentares que suportam essas florestas (SOUZA et al. 2009).

A limitação das alturas em $\mathrm{FbR}$ pode ser devido à profundidade do lençol freático, que, em geral, se apresenta bem raso nos cordões litorâneos holocênicos, com profundidades variando de 0,30 a $1,20 \mathrm{~m}$, da linha de costa para o interior da planície (SOUZA 2007). As alturas das árvores nessas florestas também aumentam nesse sentido. Nesses terrenos é frequente a ocorrência de alagamentos, devido ao afloramento do lençol freático durante as chuvas mais intensas e/ou mais prolongadas, o que pode afetar o desenvolvimento do sistema radicular das plantas. Nos terraços mais antigos o nível do lençol freático é em geral pouco mais profundo, variando de 0,70 (nas depressões) até 2,70 m (nas áreas mais elevadas), e raramente apresenta locais inundáveis.

Outro fator limitante ao crescimento dessa floresta pode ser a salinidade. Embora MOREIRA (2007) e SATO (2007) considerem que os solos da área não sejam salinos, MARTINS (2009) afirma o contrário, pois obteve salinidades de até $34,2 \mathrm{dS} / \mathrm{m}$ (a $25^{\circ}$ ) em áreas limítrofes à praia. De qualquer forma, o spray marinho também pode adentrar o interior dessas florestas, facilitado pela ação dos ventos que sopram do mar (SOUZA et al. 2009).

Conforme descrito anteriormente, à medida que se adentra a planície costeira, o substrato fica mais antigo, a floresta torna-se mais desenvolvida e ocorre aumento gradual da espessura da serapilheira, configurando assim, aporte cada vez maior de nutrientes ao solo. Da mesma forma, os solos tornam-se relativa e progressivamente melhor desenvolvidos e mais profundos.

Segundo JORGE (1975) a matéria orgânica (MO) é a grande fonte de nutrientes para as plantas, uma vez que durante o processo de decomposição vários elementos vão sendo gradualmente liberados e disponibilizados às plantas. DELITTI (1984) corrobora essa afirmação, indicando que a relação solo/serapilheira condiciona a capacidade de produção do ecossistema, sendo este o principal meio de transferência de nutrientes para o solo. Para
HAY \& LACERDA (1984 apud SILVA 1990), nos ecossistemas de restinga a $\mathrm{MO}$ é de grande importância como reservatório de nutrientes no solo, não só pelo seu conteúdo intrínseco, mas pela sua capacidade de reter nutrientes, diminuindo a sua lixiviação através do solo para fora das zonas das raízes.

Devido ao maior desenvolvimento em altura, a floresta ocupa maior espaço no perfil vertical da comunidade, o que se reflete na maior produção de biomassa viva e, consequentemente, na maior disponibilidade de biomassa morta e produção de MO no solo. De fato, a tabela 2 mostra muito bem essa relação nas florestas estudadas, sendo que os menores teores de MO estão nos Neossolos Quartzarênicos (profundidade de 0,60 m) associados aos cordões litorâneos holocênicos cobertos por FbR; esses teores aumentam progressivamente para $\mathrm{o}$ interior da planície, onde estão presentes os Espodossolos, que vão se tornando mais desenvolvidos dos terraços marinhos holocênicos (Bh de 0,50 a $1,80 \mathrm{~m}$ ) sob FaR-I para os terraços marinhos pleistocênicos (profundidade máxima do Bh de 1,25 a > 2,50 m) recobertos pela FaR-II.

De acordo com DE CONINCK (1980 apud MARTINS 2009), a circulação predominantemente vertical da água no solo comanda os processos de transporte dos compostos de matéria orgânica, ferro e alumínio que formam o horizonte B espódico, numa gênese controlada pelo lençol freático.

Ao comparar a fertilidade das florestas baixas e altas de Restinga em diferentes regiões do litoral paulista, SATO (2007) encontrou resultados semelhantes, associando-os às diferenças de quantidade de fitomassa depositada sobre os solos dessas florestas.

Estudando duas florestas de restinga vizinhas às aqui apresentadas (correlacionáveis à FaR-II e à Floresta alta de Restinga úmida), GUEDES et al. (2006) apontaram para a fragilidade de ambas, que precisam diretamente da fitomassa como fonte de reserva para sua manutenção; uma vez desmatadas, as áreas ficam expostas a perdas por erosão e lixiviação.

De maneira geral, os valores de $\mathrm{Na}, \mathrm{P}, \mathrm{Mg}, \mathrm{C} /$ $\mathrm{MO}, \mathrm{SB}, \mathrm{T}$ e $\mathrm{H}+\mathrm{Al}$ aumentam progressivamente da linha de costa para o interior da planície costeira, ou seja, dos ambientes mais jovens (FbR ou sub-bioma $\mathrm{FbR} / \mathrm{LPTb}$ ) para os ambientes mais antigos e com florestas estruturalmente mais desenvolvidas (FaR-II ou sub-bioma FaR-3/LPTb). Os valores médios de $\mathrm{Al}^{+3}$ indicam alta toxidez desse elemento nos solos das três florestas, com tendências de diminuição à medida que a floresta apresenta estrutura mais desenvolvida. 
TABELA 2 - Médias dos teores de componentes químicos de solos (profundidade de 0-20 $\mathrm{cm}$ ) coletados nas três Unidades Quaternárias de estudo. $\mathrm{MO}=$ Matéria orgânica; $\mathrm{SB}=$ soma de bases; $\mathrm{CTC}=$ capacidade de troca catiônica (efetiva); $\mathrm{T}=\mathrm{CTC}$ a pH 7; V\% = saturação por base. (Fonte: base de dados químicos de MOREIRA 2007).

\begin{tabular}{|c|c|c|c|c|c|c|c|c|c|c|c|c|}
\hline \multirow[t]{2}{*}{$U Q$} & \multirow{2}{*}{$\begin{array}{c}p H \\
\mathrm{CaCl}_{2}\end{array}$} & \multirow{2}{*}{$\begin{array}{l}M O \\
(\%) \\
\end{array}$} & $C$ & $P$ & $K$ & $\mathrm{Ca}$ & $M g$ & $A L$ & $H+A l$ & $S B$ & CTC & \multirow{2}{*}{$\begin{array}{l}V \% \\
(\%)\end{array}$} \\
\hline & & & \multicolumn{2}{|c|}{$\left(m g / d m^{3}\right)$} & \multicolumn{7}{|c|}{ - } & \\
\hline LHTb (FbR) & 3,5 & 16 & 9 & 32 & 1,4 & 3 & 3 & 34 & 159,5 & 7,6 & 41,5 & 9 \\
\hline LHTa $($ FaR-I) & 2,9 & 19 & 11,5 & 20 & 0,2 & 1,1 & 3,5 & 31,5 & 201 & 8,2 & 40 & 4 \\
\hline LPTb (FaR-II) & 3 & 19,5 & 11 & 24,5 & 0,2 & 0,9 & 4,5 & 26,5 & 240,5 & 10,6 & 37 & 4 \\
\hline
\end{tabular}

Uma análise geoestatística (SOUZA et al. 2009), baseada na localização dos pontos de amostragem e respectivos dados químicos (MOREIRA 2007), permitiu estabelecer a distribuição espacial dos diversos parâmetros químicos dos solos na área de estudo (Figura 8). Os pontos P8, P9 e P10 estão localizados no sub-bioma FbR/LHTb, P10 e P11 no sub-bioma FaR-2/LHTa (FaR-I) e P12, P13, P14, P15 e P16 no sub-bioma FaR-3/LPTb (FaR-II).
É notório o aumento gradativo dos teores de MO de P8 para P16, portanto de FbR para FaR-II. P9 destaca-se como uma anomalia nessa tendência, apresentando valores elevados de $\mathrm{MO}$ e equiparados a P16. Este fato ressalta mais um fator importante no desenvolvimento desses ecossistemas, desta vez relacionado à paleogeomorfologia desses terrenos, no caso, a presença de uma depressão entre-cordões arenosos. Neste local os solos hi-
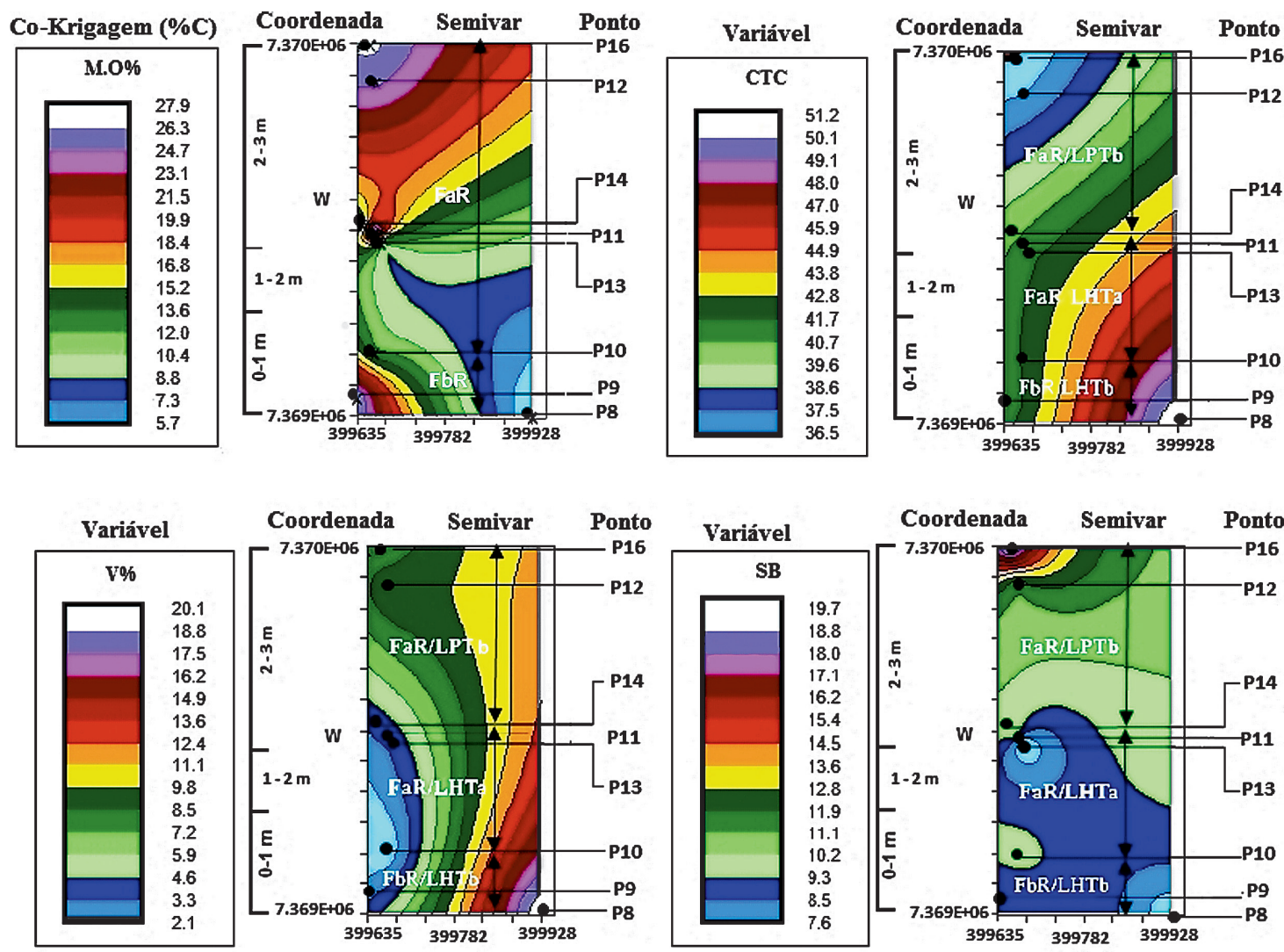

FIGURA 8 - Variabilidade espacial para a MO, CTC, V\% e SB (SOUZA et al. 2011). 
dromórficos inundáveis e o lençol freático elevado limitam o crescimento local da floresta.

Nos solos de restinga a CTC é responsável pela retenção de $\mathrm{Na}, \mathrm{K}, \mathrm{Ca}, \mathrm{Mg}$, além dos nutrientes, que são cátions metálicos como $\mathrm{Cu}, \mathrm{Mn}$ e $\mathrm{Zn}$ (SATO 2007). Consequentemente, a CTC está associada com a ciclagem dos nutrientes.

Nos solos analisados a CTC guarda uma relação inversa com a MO, de tal forma que seus maiores teores estão associados aos menores valores de CTC, indicando, portanto, que a ciclagem aumenta na direção da floresta mais estruturada (FaR-II/ LPTb), onde há maior eficiência (auto-ciclagem) quanto aos nutrientes disponibilizados para o solo, rapidamente reabsorvidos pelas plantas.

Os valores percentuais de saturação por base $(\mathrm{V} \%)$, que representam a porcentagem de $\mathrm{K}+\mathrm{Ca}+\mathrm{Mg}$ em relação à $\mathrm{CTC}$, são baixos $(<6,5 \%)$, principalmente em FaR-I (sub-bioma FaR-2/LHTa) e FaR-II (sub-bioma FaR-3/LPTb). De acordo com GUEDES et al. (2006), isso é um fator limitante do solo quanto à fertilidade para o desenvolvimento vegetal, o que é de se esperar em solos arenosos.

A SB apresenta um padrão de distribuição que também tende a aumentar da linha da costa para o interior da planície.

Esses resultados geoestatísticos indicam uma relação direta entre a maturidade estrutural das tipologias estudadas e a concentração da $\mathrm{MO}$ e dos nutrientes $\mathrm{Ca}, \mathrm{K}$ e $\mathrm{Mg}$ em conjunto (SB), confirmando a importância da biomassa morta depositada no solo para a manutenção desses remanescentes florestais.

Outros estudos sobre química dos solos realizados em diferentes ambientes da planície costeira de Bertioga (ROSSI 1999, GUEDES et al. 2006, MOREIRA 2007, MARTINS 2009) também mostraram, de maneira geral, baixos valores de soma de bases (SB) e de saturação por bases (V), predominância de solos extremamente ácidos e capacidade de troca catiônica (CTC) altamente dependente da MO.

Esses resultados indicam que a evolução pedológica deve ser considerada como fator importante no desenvolvimento da estrutura das florestas. De fato, como já destacado anteriormente, à medida que se adentra a planície e os depósitos marinhos ficam mais antigos, os solos tornam-se mais estruturados, desenvolvidos e evoluídos, passando de Neossolos quartzarênicos em FbR (LHTb) para Espodossolos em FaR (LHTa e LPTb). Portanto, essas florestas respondem à evolução pedológica dos ambientes, tornando-se mais desenvolvidas e com auto-ciclagem de nutrientes mais eficiente.

\section{CONCLUSÕES}

Diferentes padrões estruturais foram identificados nas florestas da planície costeira da bacia do rio Itaguaré. A Floresta baixa de Restinga apresenta características bem marcantes que as distinguem das outras duas comunidades de Florestas altas de Restinga, tanto em relação à distribuição dos indivíduos nas classes diamétricas, como às alturas dos indivíduos arbóreos. A análise alométrica também tornou evidente essas diferenças, mostrando correlação maior nas florestas altas de Restinga e menor na Floresta baixa.

Dentre os fatores que parecem influenciar os padrões fitofisionômicos encontrados estão atributos geológico-geomorfológicos, edáfico-pedológicos, hidrológicos e biológicos. É importante considerar que a dinâmica da paisagem envolve processos de diferentes escalas temporais e espaciais, desde a autociclagem contínua de nutrientes no solo, pela deposição da serapilheira, até a evolução geológica-geomorfológica dos ambientes sedimentares quaternários a atuais que suportam essas florestas, desencadeando diferenciações e especializações nos ecossistemas. O quimismo e a evolução pedogenética dos solos também determinam relações importantes com a maturidade estrutural das florestas, sempre associados aos diferentes estágios de autociclagem de nutrientes nos solos.

De acordo com a legislação ambiental pertinente (resoluções CONAMA 07/1996 e 417/2009), as três fitofisionomias estudadas apresentam características estruturais que sugerem o estágio avançado de regeneração para a Floresta baixa de Restinga e estado primário ou nativo para ambas as florestas altas de Restinga.

\section{AGRADECIMENTOS}

Os autores agradecem à Fundação de Amparo à Pesquisa do Estado de São Paulo pelo suporte financeiro concedido para o desenvolvimento do projeto de pesquisa (Proc. $n^{\circ}$ 2008/58549-0) e pela concessão de uma bolsa de doutorado (Proc. $n^{\circ}$ 2008/56341-2), bem como ao CNPq pela concessão de outra bolsa de doutorado (Proc. $n^{\circ}$ 143562/2008-8).

\section{REFERÊNCIAS BIBLIOGRÁFICAS}

BADEL-MOGOLLÓN, J.A.; SOUZA. C.R.G. 2010. Quantificação da perda da estrutura nas unidades quaternárias da planície costeira de Bertioga, SP (Brasil) pelo processo de artificialização do espaço. In: SEMINÁRIO 
LATINO AMERICANO DE GEOGRAFIA FÍSICA, 6 e SEMINÁRIO IBERO AMERICANO DE GEOGRAFIA FÍSICA, 2, Coimbra (Portugal), Actas, 1-12 (http://www.uc.pt/ fluc/cegot/VISLAGF/actas/tema3/jaime).

DELITTI, W.B.C. 1984. Aspectos comparativos da ciclagem de nutrientes minerais na Mata Ciliar, no Campo Cerrado e na Floresta Implantada de Pinus Elliottii var. Elliottii. Instituto de Botânica, Universidade de São Paulo, São Paulo, Tese de Doutorado, 248p.

GUEDES, D.; BARBOSA, L.M.; MARTINS, S.E. 2006. Composição florística e estrutura fitossociológica de dois fragmentos de floresta de restinga no município de Bertioga, SP, Brasil. Acta Botânica Brasílica, 20(2): 299-311.

JORGE, J.A. 1975. Matéria Orgânica. In: A.C. Moniz (coord.) Elementos da Pedologia. Rio de Janeiro, Livros Técnicos e Científicos Editora, p.169-177.

LAURENCE, W.F.; YENSEN, E. 1991. Predicting the impacts of edge effects in fragmented habitats. Biological Conservation, 55(1): 77-92.

LOPES, E.A. 2007. Formações florestais de planície costeira e baixa-encosta e sua relação com o substrato geológico nas bacias dos rios Itaguaré e Guaratuba (Bertioga - SP). Instituto de Botânica/SMA, São Paulo, Dissertação de Mestrado, 76p. + anexos.

MARTIN, L. 2003. Holocene sea-level history along eastern-southeastern Brazil. Anuário do Instituto de Geociências-UFRJ, 26: 13-24.

MARTINS, V.M. 2009. Relação solo-relevo-substrato geológico na planície costeira do município de Bertioga-SP. Escola Superior de Agricultura Luiz de Queiroz, Universidade de São Paulo, Piracicaba, Tese de Doutorado, $273 \mathrm{p}$.

MOREIRA, M.G. 2007. Associações entre os solos, os ambientes sedimentares quaternários e as fitofisionomias de planície costeira e baixa encosta nas bacias dos rios Itaguaré e Guaratuba (Bertioga-SP). Instituto de Botânica/SMA, São Paulo, Dissertação de Mestrado, 157 p.

ROSSI, M. 1999. Fatores formadores da paisagem litorânea: a Bacia do Guaratuba, São Paulo, Brasil. Faculdade de Filosofia, Letras e Ci- ências Humanas, Universidade de São Paulo, São Paulo, Tese de Doutorado, 168 p.

SATO, C.A. 2007. Caracterização da fertilidade do solo e da composição mineral de espécies arbóreas de restinga do litoral paulista. Instituto de Biociências, UNESP, Jaboticabal, Dissertação de Mestrado, 94 p.

SCOLFORO, J.R.S.; PULZ, F.A; MELO, J.M. 1998. Modelagem da produção, idade das florestas nativas, distribuição espacial das espécies e a análise estrutural. In: J.R.S. Scolforo (Org.) Manejo Florestal. Lavras, UFLA/ FAEPE, p.189-246.

SILVA, S.M. 1990. Composição florística e fitossociologia de um trecho de Floresta de Restinga na Ilha do Mel, Município de Paranaguá, PR. Universidade Estadual de Campinas, Campinas, Dissertação de Mestrado, 146 p.

SOSMA/INPE - FUNDAÇÃO SOS MATA ATLÂNTICA/INSTITUTO NACIONAL DE PESQUISAS ESPACIAIS. 2008. Atlas dos remanescentes florestais da Mata Atlântica: Período 2000-2005. Disponível em http://mapas.sosma. org.br, acessado em 05/nov./2008.

SOUZA, A.L.; MEIRA-NETO, J.A.A.; SCHETTINO, S. 1996. Avaliação fitossociológica (Relatório final do Convênio SIF/BSCEL32STO25). Viçosa, SIF/DEF, 289 p.

SOUZA, C.R.G. 2007. Ambientes sedimentares de planície costeira e baixa-média encosta em Bertioga (SP). In: ABEQUA, CONGRESSO DA ASSOCIAÇÃO BRASILEIRA DE ESTUDOS DO QUATERNÁRIO, 11, Belém, Anais, CD-ROM.

SOUZA, C.R.G.; LUNA, G.C. 2008. Unidades quaternárias e vegetação nativa de planície costeira e baixa encosta no Litoral Norte de São Paulo. Revista do Instituto Geológico, 29: 1-18.

SOUZA, C.R.G.; HIRUMA, S.T.; SALLUN, A.E.M.; RIBEIRO, R.R.; AZEVEDO SOBRINHO, J.M. 2008. "Restinga": Conceitos e empregos do termo no Brasil e implicações na legislação ambiental. Secretaria do Meio Ambiente, Instituto Geológico, São Paulo, 104p. Disponível em http://www.igeologico. sp.gov.br/ps_down_outros.asp. 
SOUZA， C.R.G.; BADEL-MOGOLLÓN， J.A.; SOBRINHO, F.A.P. 2011. Avaliação geostatística dos teores de macronutrientes em solos de dois remanescentes de Floresta de Restinga associados a depósitos marinhos holocênicos e pleistocênicos na bacia do Rio Itaguaré (Bertioga, SP). In: ABEQUA, CONGRESSO DA ASSOCIAÇÃO BRASILEIRA DE ESTUDOS DO QUATERNÁRIO, 13, Búzios, Anais, CD-ROM.

SOUZA, C.R.G., MOREIRA, M.G.; LOPES, E.A. 2009. Coastal plain and low-medium slope sub-biomes: a new approach based on studies developed in Bertioga (SP). Brazilian Journal of Ecology, 8: 1-13.

SOUZA, D.R.; SOUZA, A.L.; LEITE, H.G. 2003. Emprego de análise multivariada para estratificação vertical de florestas ineqüiâneas. $R e$ vista Árvore, 27(1): 59-63.

SUGUIO, K; MARTIN, L. 1978. Mapa geológico do litoral de São Paulo. Escala 1:100.000. Folha Bertioga. São Paulo, Secretaria de Obras e Meio Ambiente / Departamento de Águas e Energia Elétrica.

\section{Endereço dos autores:}

Felipe de Araújo Pinto Sobrinho e Jaime E. de J. Badel Mogollón - Departamento de Geografia Física, Faculdade de Filosofia, Letras e Ciências Humanas,Universidade de São Paulo, Av. Prof. Lineu Prestes, 338, CEP 05508-080, Cidade Universitária, São Paulo, SP. E-mail: felipesobrin@gmail.com.

Celia Regina de Gouveia Souza - Instituto Geológico, Secretaria do Meio Ambiente do Estado de São Paulo, Avenida Miguel Stéfano, 3900, CEP 04301-903, Água Funda, São Paulo, SP. Profa. Colaboradora do Programa de Pós-Graduação do Departamento de Geografia Física, Faculdade de Filosofia, Letras e Ciências Humanas, Universidade de São Paulo, Cidade Universitária, São Paulo, SP. E-mail: celiagouveia@gmail.com/celia@igeologico.sp.gov.br 